\title{
Hospital Expenditure as a Major Driver of Nurse Labour Force Participation: Evidence from a 10-Year Period in Canada
}

\author{
Les dépenses hospitalières comme force motrice \\ de la participation de la main-d'ouvre infirmière : \\ dix ans de données au Canada
}

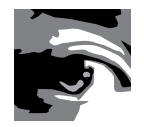

MARKO VUJICIC, MA, PHD

Senior Economist, Human Development Network

The World Bank

Washington, DC

KANECY ONATE, BA

Project Manager, CIHR Team in Community Care and Health Human Resources Department of Health Policy, Management and Evaluation

Faculty of Medicine, University of Toronto

Toronto, ON

AUDREY LAPORTE, MA, PHD

Associate Professor, CIHR Team in Community Care and Health Human Resources

Department of Health Policy, Management and Evaluation

Faculty of Medicine, University of Toronto

Toronto, ON

RAISA DEBER, PHD

Professor, CIHR Team in Community Care and Health Human Resources

Department of Health Policy, Management and Evaluation

Faculty of Medicine, University of Toronto

Toronto, ON 


\begin{abstract}
This paper examines trends in the nursing labour market in Canada over a period of dramatic fluctuations in hospital expenditures. We add to previous analysis that covered the period 19911996 and use Census data from 2001 to examine the relationship between hospital expenditure and nurse labour force participation. We find that shifts in labour force participation over the period 1991-2001 had a significant impact on the nursing supply in Canada. Individuals who were trained in nursing but were working outside the profession in 1996 because of budgetary reductions and layoffs in hospitals had largely been reabsorbed back into nursing jobs by 2001 . Our analysis provides further empirical evidence that the labour force participation among individuals trained in nursing is driven to a large extent by demand-side factors.
\end{abstract}

\title{
Résumé
}

Cet article examine les tendances du marché de la main-d’ouvre infirmière au Canada au cours d'une période qui a connu d'importantes fluctuations en termes de dépenses hospitalières. Notre travail śajoute à une analyse antérieure portant sur la période 1991-1996 et nous utilisons les données du recensement de 2001 afin d'examiner la relation entre les dépenses hospitalières et la participation de la main-d'ouvre infirmière. Nous constatons que les changements observés dans la participation de la main-d'œuvre au cours de la période 19912001 ont eu un effet significatif sur l'offre de la main-d'œuvre infirmière au Canada. Les personnes qui ont reçu une formation en soins infirmiers mais qui, en 1996, travaillaient hors de ce secteur, en raison des coupures budgétaires et des mises à pied dans les hôpitaux, ont été largement réintégrées dans le secteur infirmier dès 2001. Notre analyse offre d'autres données empiriques indiquant que l'activité de la main-d'œuvre des personnes formées en soins infirmiers dépend grandement des facteurs liés à la demande.

\section{Any argue that Canada has for several years been experiencing a $\mathrm{M}$ nursing shortage, and the situation is likely to worsen in the future (AHA 2001; Oulton 2006; CNA 2009). One often overlooked policy option for increasing} the supply of nurses is to try to recruit individuals trained in nursing who are either not working, or who are working in non-nursing jobs, back into the nursing profession. However, both in Canada and elsewhere, there is very little information on the size of this potential additional supply of nurses, the reasons these individuals choose to not work or to work in non-nursing jobs, and the impact that recruiting them back into nursing jobs would have on the supply of nurses in Canada.

This paper examines trends in the nursing labour market in Canada over a period of dramatic fluctuations in hospital expenditures. Beginning in 1992, governments throughout Canada began reducing expenditures in an effort to eliminate fiscal deficits and reduce their alarmingly high debt burden. As part of this deficit-fighting campaign, hospital expenditure lev- 
els decreased quite dramatically. Vujicic and Evans (2005) showed that nursing supply (defined as the total number of registered nurses and licensed practical nurses employed in the healthcare system) decreased during this period of hospital expenditure cut-backs, especially among the youngest age groups. Their analysis further showed that a large proportion of the young RNs and LPNs who lost their nursing jobs took up work in non-nursing occupations at $25 \%-30 \%$ lower pay levels. Thus, the hospital cut-backs of the 1990s generated a large pool of individuals who were trained to work in nursing (either as RNs or LPNs) but were working in non-nursing jobs. By 1996 there were an estimated 15,000 such individuals in Canada - a potentially significant source of nursing labour supply. Other studies covering this period in Canada also demonstrated large movement of various cadres of nursing professionals out of hospitals into other work settings or out of the labour market completely (Alameddine et al. 2005, 2009).

Since this initial analysis, the fiscal landscape has shifted dramatically. Hospital expenditure levels in Canada have increased steadily since 1996 (Figure 1). By 2001, real hospital expenditure had recovered to pre-cut-backs levels, and the increase was quite dramatic in some provinces.

Increases in health expenditure, and hospital expenditure in particular, have been shown historically to lead to an increase in the demand for health workers (Barer et al. 1984; Dussault and Vujicic 2008; Vujicic and Zurn 2006; WHO 2006). The shift in health spending patterns since 1996 in Canada, therefore, provokes several interesting policy research questions: What happened, after 1996, to the labour force participation of individuals trained in nursing in Canada? Did the share of qualified nursing staff working in non-nursing occupations drop? How big was the pool of individuals trained in nursing who were working in nonnursing occupations after hospital expenditure recovered? If these individuals had been drawn back into nursing jobs, what would have been the impact on nursing supply? This paper explores all these questions.

\section{Methodology and Data}

This paper analyzes data from the Registered Nurses' Database (RNDB) at the Canadian Institute for Health Information (CIHI) and from the Census of Canada. To work as a nurse, one must be registered by the relevant provincial or territorial regulatory college. The RNDB is a pan-Canadian database that collects demographic, education and employment information on all registered nurses in Canada, as collected under the terms of agreements with the provincial or territorial regulating authorities.

The Census of Canada allows us to identify individuals whose major field of study is nursing and who have completed at least a diploma program. Unlike other labour force surveys, this unique approach allows us to create a sample of individuals who have the educational qualification to work in nursing - what can be called the potential supply of nursing staff. Note that this nursing pool includes both RNs and LPNs, as these groups are not distinguished in the Census files. We restrict our analysis only to those with at least a diploma-level education in nursing. Thus, nursing occupations such as aides and orderlies are excluded. 
We analyze key labour market outcomes of these individuals and compare them to other occupations and over time. We use the Public Use Microdata File (PUMF) located at the University of Toronto for our analysis. This file contains aggregated education and employment data from the 1-in-30 sample that Statistics Canada aggregates from the long form in Census years.

FIGURE 1. Real health expenditure in Canada by use of funds

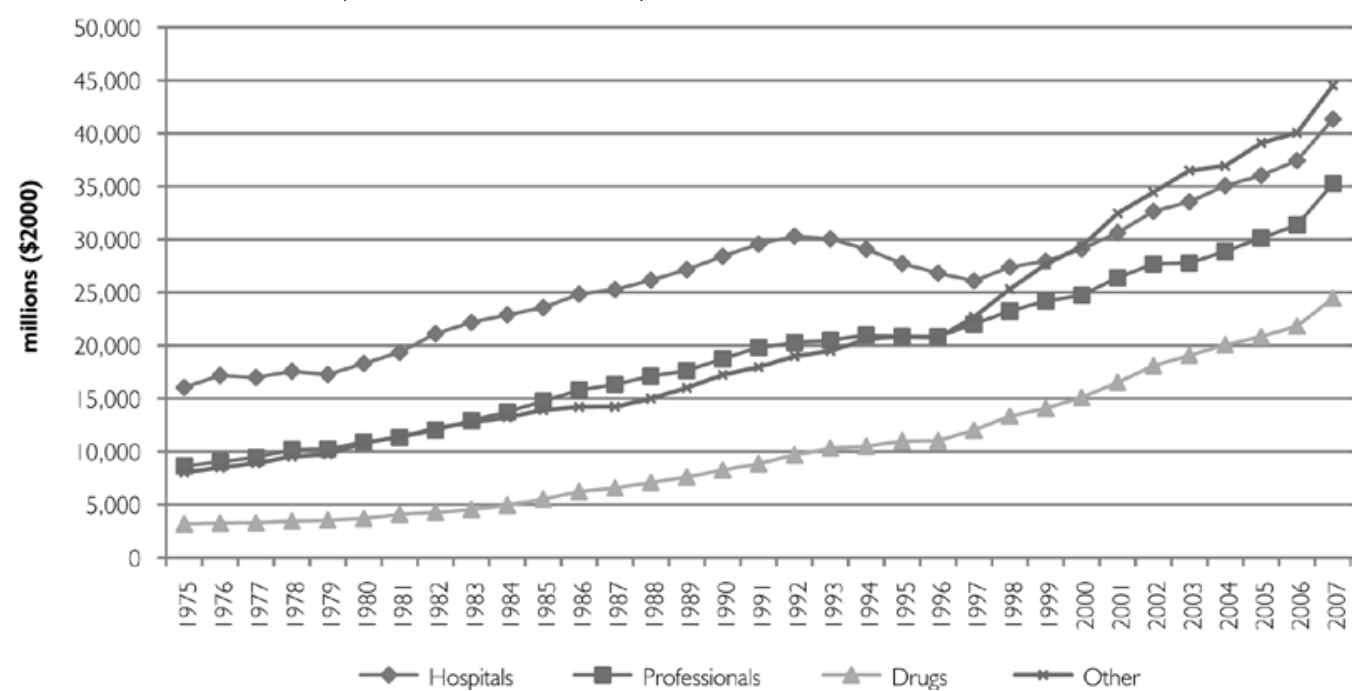

We compare results from our 2001 Census analysis to similar data from 1991 and 1996 presented in previous work (Vujicic and Evans 2005). Thus, this paper gives a picture of the nursing labour market before, during and after a period of major hospital expenditure reductions in Canada. Unfortunately, in the 2006 Census the major field of study variable was modified, and it is not possible to carry out the same analysis for 2006.

\section{Results}

\section{Labour force participation rate of nurses}

Figure 2 presents the labour force participation rate (LFPR) of all individuals who are trained in nursing by age group in Canada. The LFPR is the share of the population in each age group that is either employed, or unemployed and seeking employment. Overall, the LFPR has remained fairly stable. The only major changes are a decrease from $91 \%$ to $83 \%$ among those under 25 and a 10\% increase for those 55 and older. The national data, however, mask significant variation across provinces. For example, in 2001 the LFPR for the under- 25 age group was $77 \%$ in Quebec compared to $92 \%$ in Alberta (Figure 3). For older age groups, however, Quebec tends to have the highest value. Because $95 \%$ of individuals trained in nursing are female, we compare the labour force participation rate of these individuals with the female 
population in general. We found that those with nurse training have a slightly higher LFPR than the female population in general in Canada. We also found that provincial variation in the LFPR of those trained in nursing is explained to a very large extent by differences among females in general (results not shown).

FIGURE 2. Labour force participation rate of individuals trained in nursing

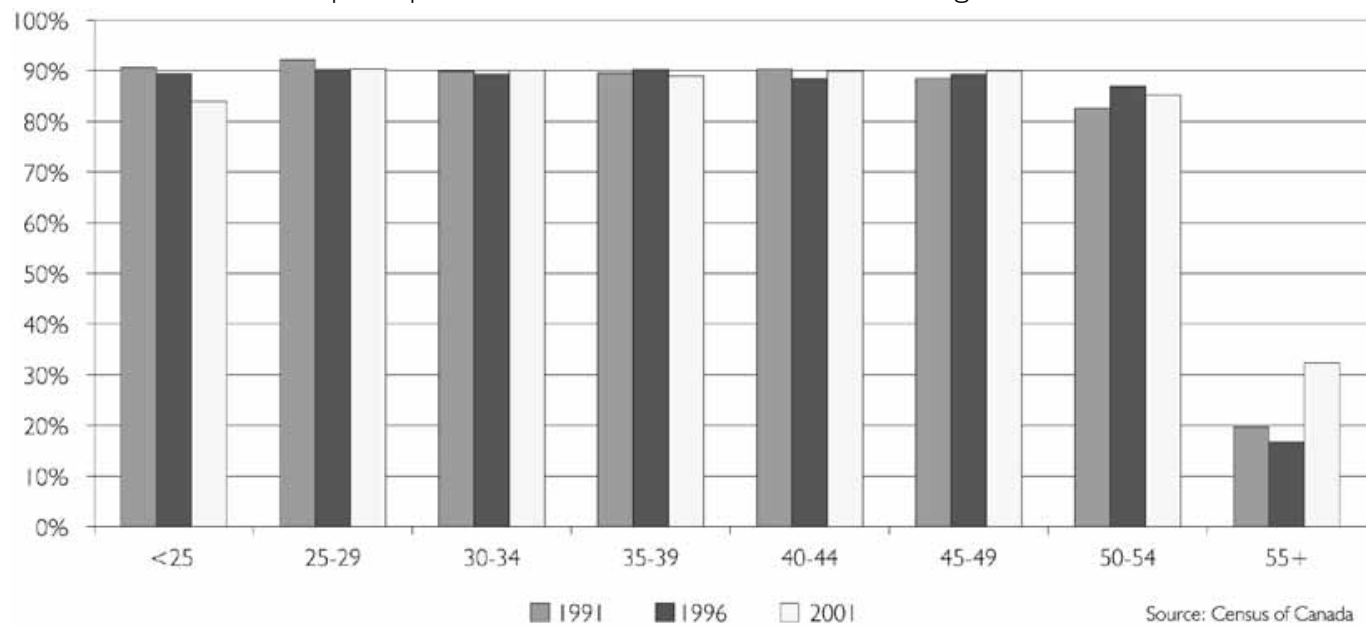

FIGURE 3. Labour force participation rate of individuals trained in nursing, select provinces

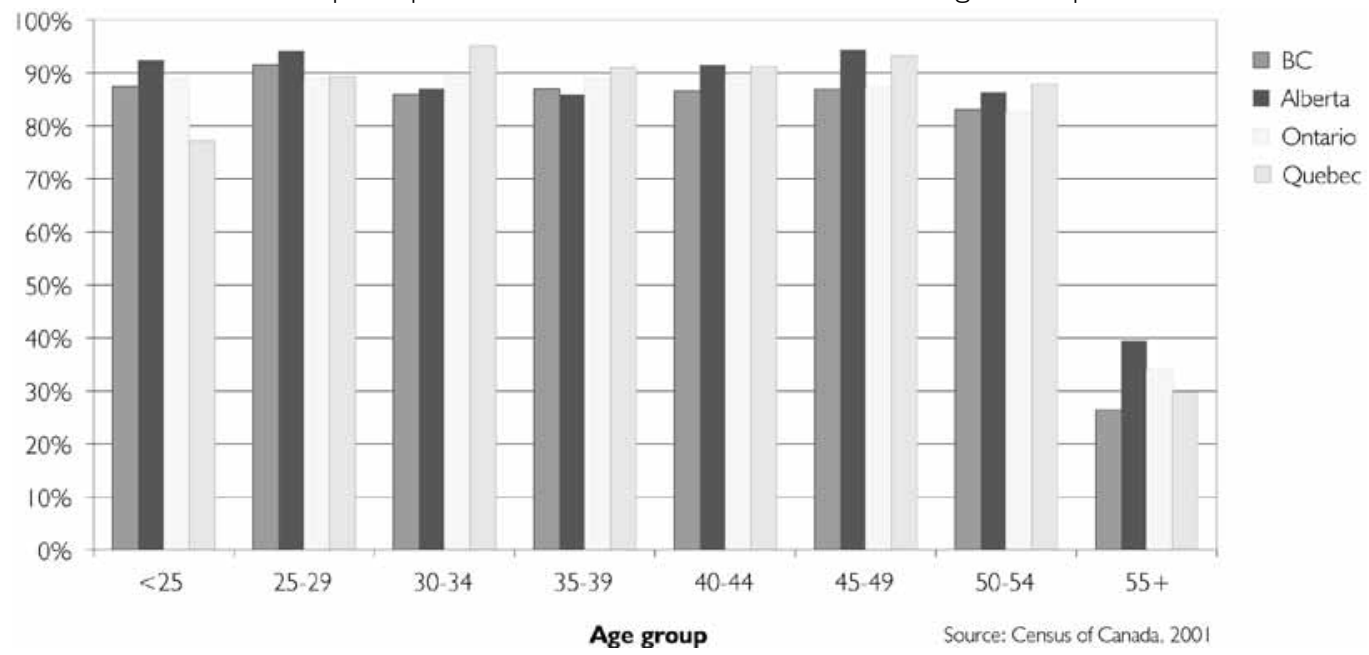

Healthcare labour force participation rate of nurses

The healthcare labour force participation rate (HCLFPR) is the share of employed individuals trained in nursing who are actually working in nursing occupations. We use the same methodology as the previous analysis (Vujicic and Evans 2005). As noted earlier, there was a sharp decrease in the HCLFPR between 1991 and 1996 for the youngest age groups. During 
this period, hospital expenditure fell dramatically in Canada; hospitals reduced hiring and laid off staff. Owing to the structure of the nursing labour market, the youngest nursing staff were most affected. Given the trends in health spending since 1996, the key policy questions are: (1) did the HCLFPR in 2001 return to 1991 levels (i.e., pre-expenditure cut-backs)? (2) were those who were working outside nursing in 1996 still working outside the profession in 2001? and (3) how did fluctuations in the HCLPR affect nursing supply?

Figure 4 shows the HCLFPR for different age groups over time. There are three main patterns of interest. First, the HCLFPR increased between 1996 and 2001 for all age groups. Second, for the youngest age groups the HCLFPR in 2001 remained below its pre-downsizing level. For example, the HCLFPR for those under 25 increased from 58\% in 1996 to $72 \%$ in 2001 but was well below the 1991 level of $80 \%$. For the 25-29 age group the same pattern holds - an increase since 1996, but not to 1991 levels. Third, for those 30 and over the HCLFP increased between 1996 and 2001 to levels that are 3-12 percentage points above the pre-cut-backs levels.

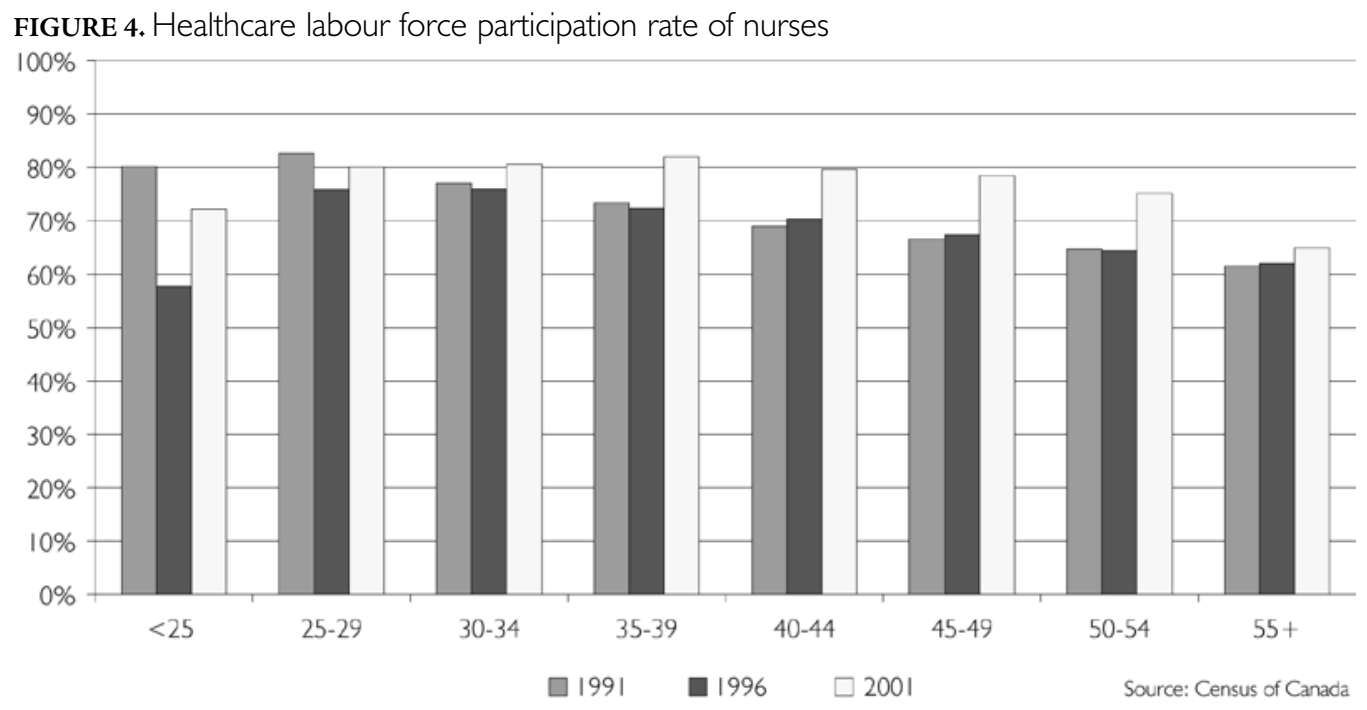

To get a sense of how changes in the HCLFPR affected nursing supply during this period, we performed some very simple simulations, which are summarized in Table 1 . The first simulation shows the impact on nursing supply in Canada in 2001 if, all else being equal, the HCLFPR in 2001 was set at its 1996 level for all age groups. Results show that under this scenario, nursing supply in 2001 would have been $8.2 \%$ lower.

The second simulation shows what would happen to nursing supply in 2001 if, all else being equal, the HCLFPR in 2001 was set at its 1991 level for each age group. Under this scenario, nursing supply in 2001 would have been $6.8 \%$ lower. This decrease is driven by the fact that the 1991 HCLFPR is smaller than the 2001 rate for those over 30 . For the under-30 age 
group, the failure of the HCLFPR to recover to 1991 levels had a relatively small impact on nursing supply in 2001 - only a $0.8 \%$ reduction.

TABLE 1. Impact of change in HCLFPR on the 200 I supply of nurses

\begin{tabular}{|c|c|c|c|c|c|}
\hline \multicolumn{2}{|c|}{$\begin{array}{c}\text { Effect on supply of nurses if HCLFPR in } \\
\text { 200 is set at 199 I level }\end{array}$} & \multicolumn{3}{|c|}{ Effect on supply of nurses if HCLFPR in } \\
\hline Age & & Cum. Tot. & Age & & Cum. Tot. \\
\hline$<25$ & $0.3 \%$ & $0.3 \%$ & $<25$ & $-0.6 \%$ & $-0.6 \%$ \\
\hline $25-29$ & $0.2 \%$ & $0.5 \%$ & $25-29$ & $-0.4 \%$ & $-0.9 \%$ \\
\hline $30-34$ & $-0.4 \%$ & $0.1 \%$ & $30-34$ & $-0.5 \%$ & $-1.5 \%$ \\
\hline $35-39$ & $-1.2 \%$ & $-1.0 \%$ & $35-39$ & $-1.3 \%$ & $-2.8 \%$ \\
\hline $40-44$ & $-1.7 \%$ & $-2.7 \%$ & $40-44$ & $-1.4 \%$ & $-4.2 \%$ \\
\hline $45-49$ & $-2.1 \%$ & $-4.8 \%$ & $45-49$ & $-2.0 \%$ & $-6.2 \%$ \\
\hline $50-54$ & $-1.5 \%$ & $-6.3 \%$ & $50-54$ & $-1.6 \%$ & $-7.8 \%$ \\
\hline $55+$ & $-0.5 \%$ & $-\mathbf{6 . 8} \%$ & $55+$ & $-0.4 \%$ & $-\mathbf{8 . 2} \%$ \\
\hline
\end{tabular}

We also simulated the effect on nursing supply in 2001 if the HCLFPR were to increase even higher. To get a sense of what value might be an upper bound, we examined industryspecific labour force participation rates for two groups: female doctors and female engineers. Their industry-specific labour force participation rates provide a rough benchmark. We followed the methodology of Boyd and Schellenberg (2007) for constructing the sample of individuals trained as physicians and engineers working in the medical and engineering professions, respectively. Figure 5 summarizes these data. It shows the share of employed females trained as physicians who were working in healthcare occupations, and the share of employed females trained as engineers who were working in engineering occupations. The rates for medicine and nursing are very similar (except for the 55-and-older age group), both of which are much higher than for engineering. If the HCLFPR for those trained in nursing is set at the rate for female doctors, nursing supply in 2001 would have been $0.6 \%$ higher. If the HCLFPR in nursing is set at $80 \%$ for all age groups, nursing supply in 2001 would have been $3.2 \%$ higher. Taken together, these simulations demonstrate clearly that changes in the HCLFPR matter because they have a significant impact on nursing supply in Canada.

Another important policy question we explored is whether those particular individuals trained in nursing but working in non-nursing jobs in 1996 were still in non-nursing jobs in 2001. Vujicic and Evans (2005) argued that the low HCLFPR among the youngest age groups in 1996 was due to hospital layoffs and was, therefore, involuntary. It was not the case that these individuals took up higher-paying non-nursing jobs. If that indeed had been the 
case, as health spending increased and more nursing vacancies opened, one would expect to see movement back into nursing jobs among this group. On the other hand, these individuals may have accumulated non-nursing human capital during the hospital downsizing period and may not have found it attractive to re-enter the nursing profession. Some of them could have been out of the nursing profession for up to 10 years.

FIGURE 5. Share of employed individuals trained in nursing, medicine and engineering working as nurses, physicians and engineers, respectively, 2001

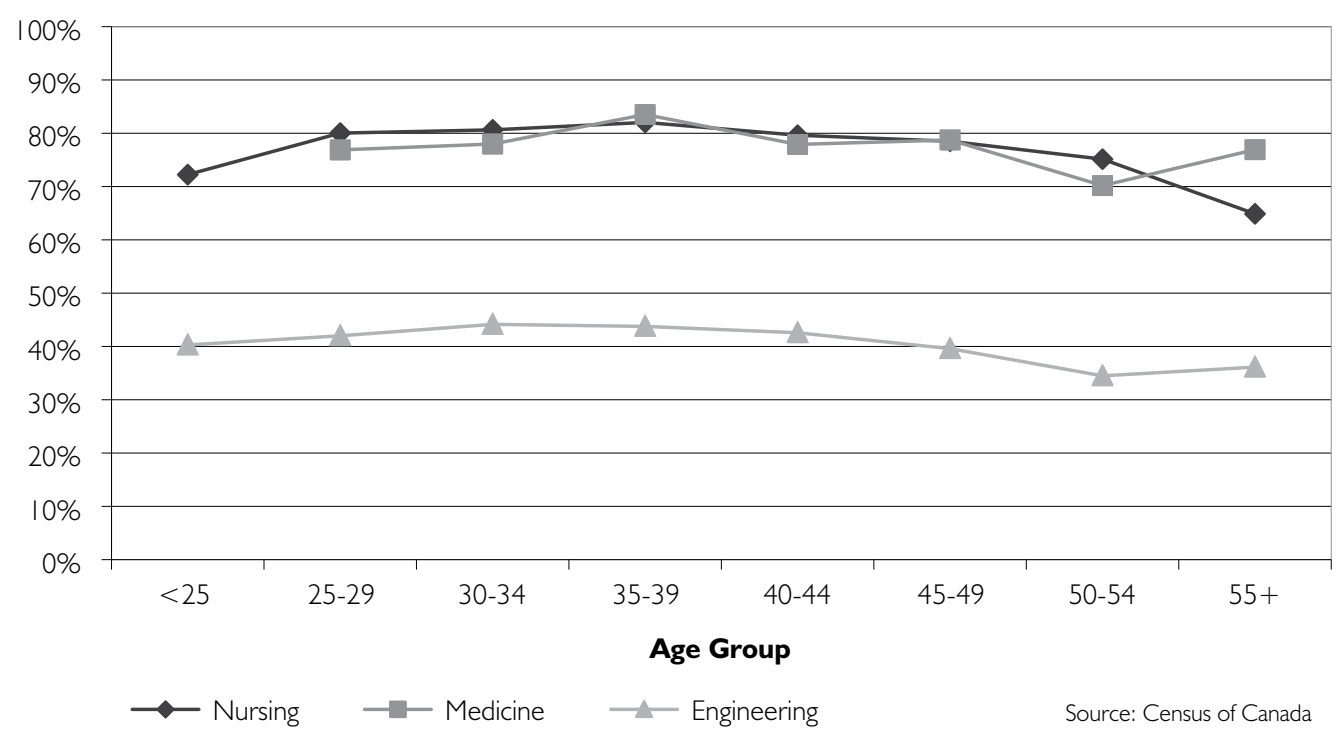

Although it is not possible to follow a panel of individuals using the Census data, it is possible to compare the HCLFPR for the under-25 age group in 1996 to the 25-29 age group in 2001. For those who were under 25 in 1996, there indeed was a movement back into nursing occupations by 2001, almost fully to 1991 levels. For those who were 25-29 in 1996, the HCLFPR in 2001 actually exceeded its 1991 value. These data suggest that the hospital expenditure reduction policies of the early 1990s did not lead to a permanent reduction in the HCLFPR among young individuals trained in nursing. Rather, those who were forced out of nursing jobs because of hospital layoffs in 1996 appear to have been reabsorbed into the nursing profession by 2001 as hospital expenditure increased.

\section{Discussion}

There are four main conclusions that emerge from our analysis. First, changes in the HCLFPR matter. Our results show that had the HCLFPR in 2001 remained at its 1996 level, total nursing supply in 2001 would have been $8.2 \%$ lower - a significant amount in an environment of labour shortages. 
Second, the changes in the HCLFPR were not uniform across different age groups during the 1991-2001 period. The HCLFPR of those under 30 recovered by 2001, but not to levels predating hospital cut-backs. For those over 30, however, the HCLFPR in 2001 was much higher than it was prior to the hospital cut-backs. Interestingly, the failure of the HCLFPR to recover to 1991 levels for those under 30 did not have a significant impact on nursing supply - it caused only a $0.6 \%$ reduction in nursing supply in 2001 . The increase in the HCLFPR since 1996 for those 30 and over more than compensated for this reduction. For the 30-andover group, the increase in the HCLFPR between 1991 and 2001 led to a 7.4\% increase in nursing supply in Canada.

Third, the pattern of the HCLFPR between 1991, 1996 and 2001 is quite similar in Quebec, Ontario, Alberta and British Columbia, the four provinces we examined. There are some differences in the magnitudes of change, but overall the age-specific HCLFPR moved in the same direction in all four provinces over the period of study.

Fourth, comparisons to other professions suggest that the HCLFPR in 2001 might have been approaching an upper threshold. Only among the oldest (55 and over) age group did there seem to be scope for further increases. But this group made up only $14 \%$ of nursing supply in 2001 (according to our sample), and marginal increases in the HCLFPR were unlikely to have a significant impact on nursing supply.

Taken together, our analysis shows that there was a significant shift in the nursing labour market between 1996 and 2001. The large pool of individuals trained in nursing but working in non-nursing jobs in 1996 had largely re-entered nursing occupations by 2001. This analysis provides further evidence to suggest that the HCLFPR is driven primarily by nursing labour demand which is, in turn, driven largely by hospital expenditure.

Should policy makers focus on recruiting trained nurses working outside nursing back into nursing jobs as a means of easing today's nursing shortage? It is not possible to gather more current data on the HCLFPR, as noted earlier. But according to the 2001 data, such a policy is likely to have minimal impact. The HCLFPR of the youngest age group in 2001 was already back to pre-cut-backs levels, and even if it were to increase further, this would have a negligible impact on nursing supply, as our simulations show. For older age groups, the HCLFPR in 2001 was much higher than pre-cut-backs levels, as well as compared to other occupations. This finding suggests little scope for further increases. As a result, our analysis would suggest that policy makers might focus on alternative strategies, such as scaling up nurse training, task shifting, relying more on migrant nurses or increasing labour productivity.

\section{ACKNOWLEDGEMENTS}

The findings, interpretations and conclusions expressed in this paper are entirely those of the authors and do not represent the views of the American Dental Association. 
Correspondence may be directed to: Marko Vujicic, Managing Vice President, Health Policy Resources Center, American Dental Association, 211 E. Chicago Ave, Chicago IL 60611, USA; e-mail:vujicicm@ada.org.

\section{REFERENCES}

Alameddine, M., A. Baumann, A. Laporte, L. O’Brien-Pallas, C. Levinton and K. Onate. 2009. “Career Trajectories of Nurses Leaving the Hospital Sector in Ontario, Canada (1993-2004)." Journal of Advanced Nursing 65(5): 1044-53.

Alameddine, M., A. Laporte, A. Baumann, L. O'Brien-Pallas and R. Deber. 2005. 'Stickiness' and 'Inflow' as Proxy Measures of the Relative Attractiveness of Various Sub-sectors of Nursing Employment." Social Science and Medicine 63(9): 2310-19.

American Hospital Association (AHA). 2001 (June)."The Hospital Workforce Shortage: Immediate and Future." AHA Trend Watch 3: 2.

Barer, M.L., A. Stark and C. Kinnis. 1984. “Manpower Planning, Fiscal Restraint, and the 'Demand' for Health Care Personnel." Inquiry 21(3): 254-65.

Boyd, M. and G. Schellenberg. 2007."Re-accreditation and the Occupations of Immigrant Doctors and Engineers." Canadian Social Trends 84: 2-10.

Canadian Nurses Association (CNA). 2009. Tested Solutions for Eliminating Canada's Registered Nurse Shortage. Retrieved March 30, 2011. <http://www.cna-nurses.ca/CNA/issues/hhr/default_e.aspx>.

Dussault, G. and M. Vujicic. 2008. “The Demand and Supply of Human Resources for Health.” In K. Heggenhougen and S. Quah, eds., International Encyclopedia of Public Health, Volume 2. San Diego: Academic Press.

Oulton, J.A. 2006."The Global Nursing Shortage: An Overview of Issues and Actions." Policy, Politics, \& Nursing Practice 7 (Suppl. 3): s34-s39.

Vujicic, M. and R.G. Evans. 2005."The Impact of Deficit Reduction on the Nursing Labour Market in Canada." Applied Health Economics and Health Policy 4(2): 99-110.

Vujicic, M. and P. Zurn. 2006. “The Dynamics of the Health Labour Market.” International Journal of Health Planning and Management 21(2): 101-15.

World Health Organization (WHO). 2006. The World Health Report 2006. Retrieved March 30, 2011. <http:// www.who.int/whr/2006/en/>. 